\title{
Recurrence of Upper Gastrointestinal Hemorrhage in Sclerotherapy X Elastic Ligature: Systematic Review
}

Sander BQ*, Veríssimo AR, Rocha GG, Martins GT, Chalita HGJ, Sindorf ML, Andreatta MFS, Rosa ED, Sena WR, Figueiredo EAS, Pessoa DF, Freitas JBA, Benvenuti ECSC, Rodrigues IW, Ferreira CO, Castro CHR, Clasen SPAS, Oliveira ASB, Marques JMG, Hoerlle FR, Avance AD, Canejo GCO, Barbosa ERA, Ribeiro MMS, Silva LT, Oliveira REM and Moura TA

Sander Medical Center, Brazil

*Corresponding author: Sander BQ Sander Medical Center, Brazil.

Received Date: April 01, 2021

Published Date: April 16, 2021

\section{Introduction}

Introduction: The first technique to be used as an intervention in this procedure was sclerotherapy, but with the passing of the years and improvement it was found in the elastic ligature technique the gold standard for the approach in these cases.

Objectives: To compare, through a systematic review, the recurrence of upper digestive hemorrhage in the techniques of sclerotherapy and elastic ligation.

Methods: The most relevant studies in the MedLine, Bireme and Scielo databases were analyzed. The search strategy used the following keyword combinations: ("High Digestive Hemorrhage, Sclerotherapy, Elastic Bandage").

Results: There were 9 studies selected from the crossword of the keywords, and of these, only 6 were used in the studies after applying the Randomized Controlled Trial and Clinical Trials filters.

Conclusion: There is no definite consensus on which technique - sclerotherapy or elastic ligation - could be associated with a lower risk of recurrence in cases involving upper gastrointestinal bleeding. The literature shows advantages both in the technique of sclerotherapy and in the technique of elastic ligation, and in general, it is nowadays observed that the technique considered gold standard for these cases is the technique of elastic ligation, although many professionals still opt for sclerotherapy, especially in surgical intervention in pediatric patients.

Keywords: Upper gastrointestinal bleeding; Sclerotherapy; Elastic ligation

\section{Introduction}

Upper gastrointestinal bleeding is an important medical emergency, with a high rate of morbidity and lethality [1]. Over the past few years, a significant evolution in the methods and techniques available has been observed. Endoscopic therapy, whether with elastic ligation or sclerotherapy, is the most indicated for the management of upper gastrointestinal bleeding and for post-bleeding treatment [2]. However, both techniques have advantages and disadvantages, as well as different statistics about the likelihood of recurrences and rebleeds. This complication is

conceptualized as gastrointestinal bleeding proximal to the Treitz angle, which has an increasing incidence due to the aging of the population and its comorbidities [3]. In addition, the causes of upper gastrointestinal bleeding may be due to non-varicose factors, or bleeding from esophageal varices, with a total of $80 \%$ of cases resulting from the first type mentioned [3].

Although the mortality rate from upper gastrointestinal bleeding has declined over the years, as a result of the implementation of several more effective treatment and care modalities, its mortality 
rates still reach the $20 \%$ range in up to 6 weeks [2]. The rate of a first episode of bleeding from varicose veins is $5-15 \%$ in 1 year and its risk is defined by the size of the varicose veins, presence of red signs, severity of liver disease and continuous alcohol intake. Among the prognostic factors, the size of the varicose vein is the most important, and the larger the caliber, the greater the risk of bleeding [2]. In view of these previous considerations, the objective of the present study was to compare, through a systematic review, the recurrence of upper digestive hemorrhage in the sclerotherapy and elastic ligation techniques.

\section{Method}

The most relevant studies originally published in the English

Chart 1: Inclusion and exclusion criteria applied in the selection of studies.

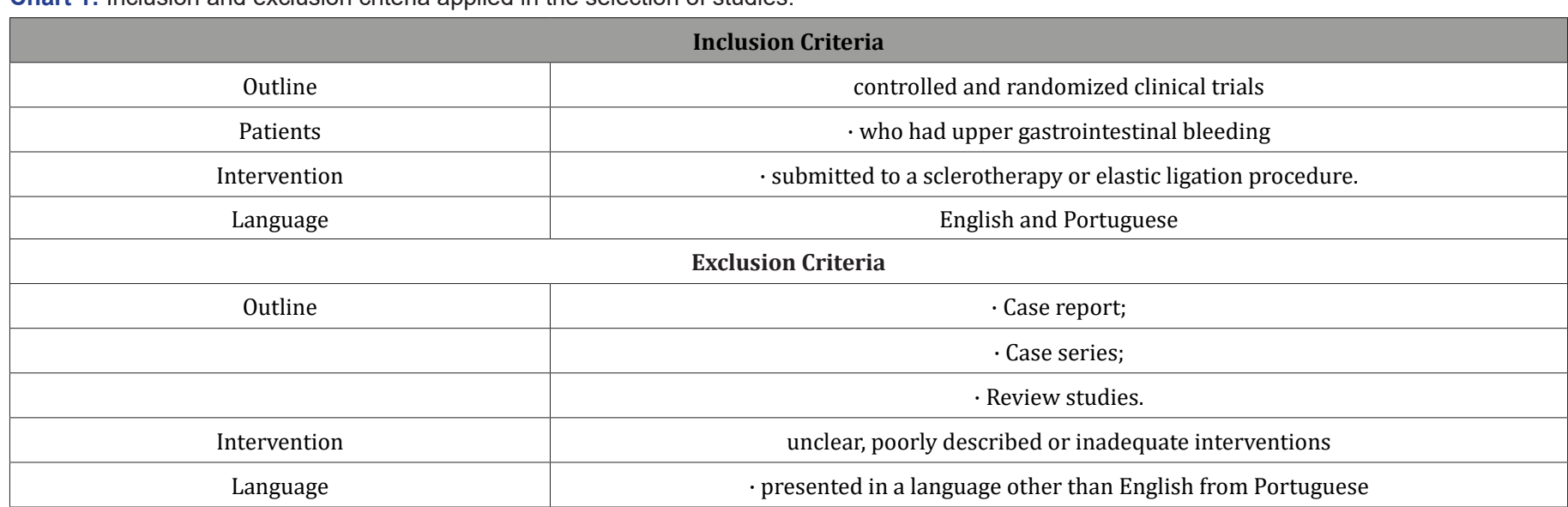

Table 1: Summary of studies and their main results.

\begin{tabular}{|c|c|c|c|}
\hline Author & Study & Intervention & Outcomes \\
\hline $\begin{array}{l}\text { Pimenta, } \\
\text { et al. [23] }\end{array}$ & $\begin{array}{l}\text { Prospective study } \\
\text { with } 85 \text { patients } \\
\text { under } 18 \text { years of } \\
\text { age with portal } \\
\text { hypertension, } \\
\text { cirrhotic and } \\
\text { non-cirrhotic. }\end{array}$ & $\begin{array}{l}\text { Secondary endoscopic } \\
\text { prophylaxis was performed } \\
\text { through LE or sclerotherapy. } \\
\text { Varicose vein eradication, } \\
\text { incidence of rebleeding, } \\
\text { number of endoscopic } \\
\text { sessions required for erad- } \\
\text { ication, incidence of gastric } \\
\text { varicose veins and portal } \\
\text { hypertension gastropathy } \\
\text { were evaluated. }\end{array}$ & $\begin{array}{l}\text { LE was performed in } 34(40 \%) \text { patients and sclerotherapy in } 51(60 \%) \text {. Bleeding } \\
\text { from rupture of esophageal varices occurred in } 36(42.3 \%) \text { patients and was more } \\
\text { prevalent in the group undergoing sclerotherapy. Patients undergoing LE had lower } \\
\text { rates of rebleeding ( } 26.5 \% \text { vs } 52.9 \%) \text { and fewer sessions required to eradicate } \\
\text { esophageal varices ( } 3.5 \text { vs } 5) \text {. It was concluded that the endoscopic LE probably } \\
\text { has lower rebleeding rates and a smaller number of sessions necessary to eradicate } \\
\text { esophageal varices, when compared to sclerotherapy. }\end{array}$ \\
\hline $\begin{array}{l}\text { Araújo, et } \\
\text { al. [11] }\end{array}$ & $\begin{array}{l}\text { A documentary, } \\
\text { prospective and } \\
\text { exploratory study } \\
\text { with a quantita- } \\
\text { tive approach was } \\
\text { carried out. }\end{array}$ & $\begin{array}{l}\text { Data collection was carried } \\
\text { out between August and No- } \\
\text { vember } 2014 \text {, using a form } \\
\text { containing sociodemograph- } \\
\text { ic and clinical questions, } \\
\text { using } 76 \text { medical records. }\end{array}$ & $\begin{array}{c}\text { The predominance of male patients }(63.2 \%) \text {, in the age group between } 61 \text { to } 80 \\
\text { years old }(48.7 \%) \text {, with hematemesis as the most common clinical manifestation } \\
(53.9 \%) \text { was highlighted. The prevalent endoscopic diagnosis was peptic ulcer } \\
(34.3 \%) \text {. The predominant hospitalization period was between } 4 \text { and } 10 \text { days } \\
(40.8 \%) \text { and } 21 \% \text { of the patients died. It was concluded that the knowledge of the } \\
\text { injuries that cause HDA and the characteristics of this type of patient can assist } \\
\text { managers in planning actions that have an impact on the quality of the treatment } \\
\text { employed. }\end{array}$ \\
\hline $\begin{array}{l}\text { Arruda, et } \\
\text { al. [20] }\end{array}$ & Literature review & $\begin{array}{l}\text { Literature review based on } \\
\text { the results of articles pub- } \\
\text { lished in the last } 10 \text { years }\end{array}$ & $\begin{array}{l}\text { They stated that injection sclerotherapy is a simple, inexpensive and effective thera- } \\
\text { peutic technique for obtaining hemostasis, widely used in the endoscopic treatment } \\
\text { of patients with HDA. Endoscopic sclerotherapy can be used in urgent situations } \\
\text { with active bleeding, in the immediate prevention of a possible rebleeding and in } \\
\text { secondary prophylaxis with the eradication of varicose veins and prevention of a } \\
\text { late rebleeding. This method is associated with a high risk of rebleeding after deflat- } \\
\text { ing the balloon, but it is a temporary viable alternative in controlling bleeding when } \\
\text { other techniques are not available. }\end{array}$ \\
\hline
\end{tabular}




\begin{tabular}{|c|c|c|c|}
\hline $\begin{array}{l}\text { Leal, et al. } \\
\text { [19] }\end{array}$ & $\begin{array}{c}\text { A cross-sectional } \\
\text { study was carried } \\
\text { out. }\end{array}$ & $\begin{array}{l}\text { A form built for this research } \\
\text { was applied, containing the } \\
\text { clinical, epidemiological and } \\
\text { endoscopic variables of the } \\
\text { patients who underwent EDA } \\
\text { due to the episode of HDA, } \\
\text { from January to August } 2012 \text {. }\end{array}$ & $\begin{array}{l}60 \text { cases were registered, the average age was } 63.80 \text { years, } 74.5 \% \text { were male. The } \\
\text { main cause of HDA was peptic ulcer ( } 56.4 \%) \text {, followed by esophageal varices }(20 \%) \text {. } \\
\text { Of the } 43 \text { patients with non-varicose HDA, } 37.1 \% \text { underwent endoscopic therapy, } \\
\text { most of them sclerotherapy, while in those with varicose HDA, 83.3\% were treated } \\
\text { endoscopically (all with LE). Bleeding reported in } 18.2 \% \text {. It was concluded that } \\
\text { HDA can be life-threatening and endoscopic therapy is an important resource for } \\
\text { reducing mortality, rebleeding and the need for surgery. }\end{array}$ \\
\hline $\begin{array}{l}\text { Batis- } \\
\text { ta-Neto, et } \\
\text { al. [14] }\end{array}$ & $\begin{array}{l}\text { Prospective and } \\
\text { observational study }\end{array}$ & $\begin{array}{l}\text { Schistosomal patients } \\
\text { with a history of HDA who } \\
\text { underwent splenectomy + li- } \\
\text { gation of the left gastric vein } \\
\text { and sclerotherapy partici- } \\
\text { pated. The variables studied } \\
\text { were the evolutionary profile } \\
\text { of esophageal varices before } \\
\text { and after the operation and } \\
\text { the rate of hemorrhagic } \\
\text { recurrence. }\end{array}$ & $\begin{array}{l}\text { The sample consisted of } 30 \text { patients distributed, according to gender, in } 15 \text { patients } \\
\text { for each sex. Age ranged from } 19 \text { to } 74 \text { years (median = } 43 \text { years). The eradication } \\
\text { of varicose veins with sclerotherapy was achieved in } 86.7 \% \text { and exclusively with the } \\
\text { operation in } 15.4 \% \text { of patients. One to seven sessions of sclerotherapy were perfor- } \\
\text { med and an average of three per patient to eradicate varicose veins. Four patients } \\
\text { (13.3\%) did not complete the follow-up. Hemorrhagic recurrence was } 16.7 \% \text {. In the } \\
\text { authors' conclusion, there was a reduction in the degree, caliber and red spots of } \\
\text { esophageal varices in all patients. }\end{array}$ \\
\hline $\begin{array}{l}\text { Santos, et } \\
\text { al. [8] }\end{array}$ & Literature review & $\begin{array}{l}\text { Secondary prophylaxis is in- } \\
\text { dicated for all patients with } \\
\text { bleeding from esophageal } \\
\text { varices. In adults, the method } \\
\text { considered to be the most } \\
\text { effective is the combined use } \\
\text { of beta-blocker and LE. In } \\
\text { childhood, there is no con- } \\
\text { sensus on the best form of } \\
\text { prophylaxis and most studies } \\
\text { are case series reports. }\end{array}$ & $\begin{array}{l}\text { Only one study, not randomized, compared sclerotherapy alone or associated with } \\
\text { propranolol and there was no benefit with the association. Thus, there is no con- } \\
\text { sensus on the best way to perform secondary prophylaxis in children. Endoscopic } \\
\text { therapy has been shown to be effective in eradicating esophageal varices, however, } \\
\text { the role of propranolol in pediatrics has yet to be defined. }\end{array}$ \\
\hline
\end{tabular}

Caption: HDA (Upper Digestive Hemorrhage); EDA (Upper Digestive Endoscopy); LE (Elastic Bandage).

\section{Result}

By crossing the keywords sclerotherapy, elastic ligation and upper gastrointestinal bleeding, it was possible to obtain an initial sample of 9 articles. However, after applying the Randomized Controlled Trial and Clinical Trials filters and after reading the articles found, 6 articles were selected involving the theme and which were then part of the final sample. In Table 1 we will present a summary of the works selected and reviewed in the present study.

\section{Discussion}

Through this study, we sought to compare the recurrence of upper gastrointestinal bleeding in the sclerotherapy and elastic ligation techniques, pointing out the consensus that exists on this topic in national and international literature. What are the risks of each of these techniques? Which is more prone to recurrences and what are the advantages and limitations of each one in particular? Analyzing the results obtained through the bibliographic survey, it was possible to observe that both techniques have important advantages and are perfectly indicated. However, in short, the literature allows us to conclude that the technique considered the gold standard for these cases is the technique of elastic ligation, which is the one with the lowest risk of recurrences in comparison to the sclerotherapy technique, although many professionals still choose to use the technique of sclerotherapy, especially in surgical intervention in pediatric patients. This finding was evident in several of the most recent studies that highlighted the fact that sclerotherapy is a pioneering technique in this type of intervention, and although it is still widely used, its usefulness has fallen a lot since the appearance and improvement of the technique of elastic ligation. Sclerotherapy was the first option available, in terms of technique, to be used in these cases. However, over the years and with the evolution of available techniques and materials, the technique of elastic ligation started to gain its space and is currently recommended as being the gold standard in these cases $[2,3]$.

Guidoux, et al. [7] who added that, after the advent of elastic ligation, the preference for sclerotherapy has been revised, since, in the authors' view, elastic ligation has lower rates of morbidity. Also, according to Guidoux, et al. [7] over the years, the elastic bandage has been replaced, representing, in the survey carried out in a hospital unit by these authors, a total of $76 \%$ of the cases in which surgical intervention related to upper gastrointestinal bleeding was required. However, in many situations, the use of sclerotherapy is still highly recommended, considering the advantages attributed by many to this technique. Specifically analyzing the issue of the occurrence of recurrences, it was possible to observe that most of the studies listed here presented data on this topic, a topic of great importance when talking about rehabilitation in these cases. Thus, the analyzed literature presented several studies comparing the occurrence of recurrences between both techniques. It was possible to observe that, in general, the results showed that the technique of elastic ligation is the most used and considered the one of choice when it comes to prevention of cases of variceal bleeding. However, 
there was no consensus on which technique can be considered the most effective when the theme is the prevention of the occurrence of recurrences.

In the study by Zanette, et al. [6], the authors stated that elastic ligation of esophageal varices is as effective as sclerotherapy itself, but also highlighted that the technique of elastic ligation is the one that most presented, according to the literature review, a higher frequency of recurrences. than the sclerotherapy technique. Among the studies that pointed to a higher risk of recurrence in the elastic ligation technique is Santos8, which obtained a rate of recurrence and greater complications in the elastic ligation technique compared to the cyanoacrylate injection technique. Also, in the study by Leal, et al, [19] in their study they observed that the rate of rebleeding after elastic ligation was common in $18.2 \%$. It was also possible to observe that the patients who had recurrences were also the ones who had a high mortality rate. Otherwise, some authors have pointed out that there are no differences between the results obtained, in terms of recurrence, in the use of the technique of elastic ligation and sclerotherapy. This was evident in the study by Luz [9] who found similar results, which suggest that sclerosis and elastic ligation are equally effective in controlling acute variceal hemorrhage.

Now analyzing the results obtained with the sclerotherapy technique in terms of recurrences, it was possible to observe that some authors defended this technique as the safest and with the lowest risk of recurrences. This was observed in the study by Santos, et al. [13] who stated that this technique is the most used in children due to its safety and effectiveness, and that the risk of new episodes of upper gastrointestinal bleeding is low (0 to $11.9 \%$ ), being the most cases from gastric varices or duodenal ulcer. Another advantage of this technique is the fact that it presents a low risk of serious complications, although mild reactions have been frequently reported. Also, in the study by Batista-Neto, et al. [14], sclerotherapy was performed on 30 patients, with a recurrence rate of $16.7 \%$. To our understanding, analyzing the recurrence rates of the studies by Batista-Neto, et al. [14], who evaluated the relapse in sclerotherapy, and the study by Leal, et al. [19] who evaluated the rate in cases of elastic ligation, were very similar, reaching $16.7 \%$ and $18.2 \%$ respectively. In the study by Pimenta, et al. [23], which was carried out with 85 patients, the authors observed that rebleeding was more frequent in patients undergoing sclerotherapy, reaching $42.3 \%$ in relation to the group submitted to elastic ligation, which reached $26.5 \%$.

It is also noteworthy that the occurrence of uppergastrointestinal bleeding represents an important medical emergency, which requires immediate hospitalization and specialized intervention, in view of the risk of death. Initially analyzing the mortality rate of this type of pathology, according to the vision of Luz, et al. [2], this complication can present a rate of up to $20 \%$ of mortality, with a period of up to 6 weeks after the occurrence of the event. The occurrence of these cases has been associated with population aging in agreement with the comorbidities associated with it [3]. Studies have pointed out that the risks will depend on the severity and size of the varicose vein and the size of the varicose vein is still a factor considered essential in order to have a definition of the prognosis of each case [2]. In view of its risks, it is known that the therapeutic options in these cases are quite restricted. Therefore, in these situations, surgical intervention is recommended especially in those cases where treatment and endoscopic retreatment are not effective, according to Lourenço and Oliveira [5]

Therefore, in view of all the results obtained, we consider that it is not possible to present a definitive position as to which technique - sclerotherapy or elastic ligation - is the most effective in preventing recurrences in upper gastrointestinal bleeding. We also consisder that the evidence indicates that the sclerotherapy technique has been advocated as safer for pediatric patients, but that the technique of elastic ligation is considered the gold standard for cases of upper gastrointestinal bleeding in general, being preferred by a wide variety of professionals trained to carry out such intervention.

\section{Conclusion}

In view of the results found, there is no definitive consensus on which technique - sclerotherapy or elastic ligation - could be associated with a lower risk of recurrences in cases involving upper gastrointestinal bleeding. The literature points out advantages both in the sclerotherapy technique and in the technique of elastic ligation, and, in general, it is currently observed that the technique considered the gold standard for these cases is the technique of elastic ligation, although many professionals still opt for the use of sclerotherapy, especially in surgical intervention in pediatric patients.

\section{Acknowledgement}

None.

\section{Conflict of Interest}

No conflict of interest.

\section{References}

1. Almeida TC, Domingues ALC, Chaves KFCS, Costa AB, Almeida RC (2013) Etiology of upper gastrointestinal bleeding in an emergency hospital in Recife - Pernambuco. GED Gastroenterol. Endosc Vol. 32(3).

2. Luz HLJ, Linhares CM, Souto LF, Canfield BLZX, Badotti A (2017) Prognostic factors and mortality in cirrhotic patients who were hospitalized with varicose upper digestive hemorrhage in a public hospital. Architect Catarin Med 46 (1): 97-106.

3. Castro MXF (2014) Clinical-epidemiological profile of patients treated with complaints suggestive of upper gastrointestinal bleeding in the emergency department of a tertiary hospital in São Paulo. Course Conclusion Paper (Specialization) USP São Paulo pp. 44. 
4. Carvalho E, Nita MH, Paiva LMA, Silva AAR (2000) Digestive bleeding. pediatr (Rio J.) 76(Suppl.2): S135-S146.

5. Lourenço KG, Oliveira RB (2003) Approach to the patient with nonvaricose upper gastrointestinal bleeding. Medicine Ribeirão Preto 36: 261-265.

6. Zanette M, Pereira-Lima JC, Lopes CV, Mattos AA (2003) The extinction of esophageal varicose veins by elastic ligation alters the portal pressure in cirrhotics. AMRIGS Porto Alegre Magazine 47(1): 46-49.

7. Guidoux GN, Oliveira JR, Andrade LC, Carrijo AC (2004) Treatment of esophageal varices with sclerosis $x$ elastic ligation. III SEMIC - UNIFENAS Scientific Initiation Seminar.

8. Marcus Melo Martins Santos, Luciano Henrique Lenz Tolentino, Rodrigo Azevedo Rodrigues, Frank Shigueo Nakao, Maria Rachel da Silveira Rohr, et al. (2011) Endoscopic treatment of esophageal varices in cirrhotic patients: elastic ligation versus cyanoacrylate injection. Eur J Gastroenterol Hepatol 23(1): 60-65.

9. G0 light (2008) Comparison of endoscopic sclerosis with elastic ligation for the treatment of the acute phase of hemorrhage by rupture of esophageal varices. Dissertation (master's in surgery of the Digestive System) - Faculty of Medicine, University of São Paulo, São Paulo.

10. Moura EGH, Benevides G, Moura ET, Ishioka S (2009) Varicose upper digestive hemorrhage: evaluation and therapy. GED gastroenterol. Endosc 28(4): 121-132.

11. Araújo EA, Torres FSC, Carneiro FS, Costa KV, Guiotti MTG, et al. (2010) Prophylaxis of gastrointestinal bleeding in emergency medicine. Rev Soc Bras Clin Med Vol. 8(4).

12. Haro CP, Fey A (2010) Analysis of the epidemiological profile, treatment and evolution of patients with upper gastrointestinal bleeding treated at the emergency department of Hospital Regional Alto Vale. Santa Catarina Archives of Medicine Vol. 39(3)

13. Santos JMR, Ferreira AR, Fagundes EDT, Ferreira APS, Ferreira LS, et al. (2011) Secondary endoscopic and drug prophylaxis in children and adolescents with esophageal varices. Rev med Minas Gerais 21(4-S1) 28-34.
14. Batista-Neto J, Tognetti LB, Ribeiro LT, Balwani MC, Muritiba T, et al. (2013) Evolutionary profile of esophageal varices after splenectomy associated with ligation of the left gastric vein and sclerotherapy in schistosomal portal hypertension. Arq Bras Cir Dig 26(1): 49-53.

15. Pereira FMF, Evangelista-Neto J, Brito N, Amaral F, Fonseca-Neto OCL, et al. (2013) Angiographic and blood pressure changes determined by splenectomy and ligation of the left gastric vein in patients with schistosomiasis mansoni. Arq Bras Cir Dig 26(4): 302-308.

16. Figueiredo M, Figueiredo MF (2013) Research on liquid sclerotherapy in varicose veins of the lower limbs. J Vasc Bras 12(1): 10-15.

17. Lima JC (2013) Upper non-varicose gastrointestinal bleeding: experience at Unicocent Gastrocentro. Course conclusion work (Master's), State University of Campinas, Faculty of Medical Sciences pp. 84.

18. Coelho FF, Perini MV, Kruger JAP, Fonseca GM, Araújo RLC, et al. (2014) Treatment of upper gastrointestinal bleeding from esophageal varices: current concepts. Arq Bras Cirur Dig 27(2): 138-144.

19. Leal VP, Bianchini F, Totti SR (2014) Evaluation of the clinical, epidemiological and endoscopic characteristics of patients with upper gastrointestinal bleeding in a hospital in the south of Santa Catarina. GED gastroenterol endosc Di. Pp. 33(1).

20. Arruda LC (2015) The pharmacist assisting patients with upper gastrointestinal bleeding. Course Conclusion Paper (Specialization in Clinical and Hospital Pharmacy), Educational Training Center and Hospital Pharmacy, UFPB, Recife, PB.

21. Araújo SM, Alexandre ACS, Albuquerque APS (2016) Endoscopic findings in users affected by upper gastrointestinal bleeding in an emergency. Rev Enfer UFPE on line 10(5): 1694-1700.

22. Pimenta JR, Ferreira AR, Bittencourt PFS, Franco Neto JÁ, Carvalho SD, et al. (2016) Approach to digestive hemorrhage in children and adolescents. Rev Med Minas Gerais 26(Suppl 6): S27-S37.

23. Pimenta JR, Ferreira AR, Fagundes EDT, Bittencourt PFS, Moura AM, et al. (2017) Evaluation of endoscopic secondary prophylaxis in children and adolescents with esophageal varices. Arq Gastroenterol 54(1): 21-26. 